East African Medical Journal Vol. 84 No. 3 March 2007

LOWER LIMB AMPUTATIONS AT THE KENYATTA NATIONAL HOSPITAL, NAIROBI

K.O. Awori, MBChB, MMed (Surg), Assistant Lecturer, Department of Human Anatomy, College of Health Sciences, University of Nairobi and Senior Registrar, Division of Orthopaedics, Kenyatta National Hospital, Nairobi and J.E.O. Ating'a, MBChB, MMed (Surg), MCh (Ortho), Associate Professor, Department of Orthopaedic Surgery, College of Health Sciences, University of Nairobi and Consultant Orthopaedic Surgeon, Division of Orthopaedics, Kenyatta National Hospital, P.O. Box 19676-00100, Nairobi, Kenya

Request for reprints to: Dr. K.O. Awori, Department of Human Anatomy, College of Health Sciences, University of Nairobi, P.O. Box 30197-00100, Nairobi, Kenya

\title{
LOWER LIMB AMPUTATIONS AT THE KENYATTA NATIONAL HOSPITAL, NAIROBI
}

\author{
K.O. AWORI and J.E.O. ATING'A
}

\begin{abstract}
Objective: To determine the causes and pattern of lower limb amputations at the Kenyatta National Hospital.

Design: Descriptive prospective study.

Setting: The Kenyatta National Hospital between July 2003 and June 2004.

Results: A total of 77 lower limb amputations (LLA) were performed on 74 patients. The age ranged from seven months to 96 years (mean $44.8 \pm 22.5$ ). Forty six patients $(62.1 \%$ ) were male. Majority of the patients $(\mathbf{8 9 . 1 \% )}$ ) had primary or no formal education, forty one $(55.4 \%)$ were unemployed, with $39 \%$ self employed in the informal sector. Peripheral vascular diseases were the main indication for LLA (55.3\%), 13 patients (17.5\%) due to diabetes-related gangrene. Eighteen patients $(24.3 \%)$ had tumours, mainly osteogenic sarcoma (16.2\%), while trauma accounted for $18.9 \%$. Forty two (55\%) of the amputations were above-the-knee, $24(31 \%)$ below-the-knee, four $(5 \%)$ hip disarticulations and seven $(9 \%)$ were foot amputations.

Conclusion: This study found peripheral vascular diseases unrelated to diabetes to be the main indication for lower limb amputations at Kenyatta National Hospital contrary to previous institutional and loco-regional studies which report trauma as the leading cause. Further investigation into vascular causes is therefore recommended.
\end{abstract}

\section{INTRODUCTION}

Rates of amputations vary significantly both between and within countries (1). This is due to socio-economic and organisational environment and the clinicians' decision making (2). A previous institutional study found trauma and tumours to be the leading causes of LLA (3). Similar findings have been reported by local and regional studies (4-7). A rise in the global burden of diabetes mellitus and its complications has been reported (8). The prevalence of diabetes has been found to be related to the incidence of lower limb amputations in some regions of the world (1). At the Kenyatta National Hospital, there has been a steady increase in the number of patients presenting with diabetes and its related complications (9). This study was performed to establish the current pattern of indications of lower limb amputation at the Kenyatta National Hospital.

\section{MATERIALS AND METHODS}

Design: This is a descriptive analysis of prospectively collected data on patients who underwent amputations of the lower limb. 
Study site: Kenyatta National Hospital, the largest teaching and referral hospital in Kenya. It provides subsidised services to patients from the neighbouring towns and those referred from peripheral hospitals. Special medical services from diabetes care to orthopaedic and cardiovascular surgery are offered by teams of specialists.

Materials and methods: The study was approved by the institution's ethical and research committee before data were collected. Data were collected by one of the authors (KOA) using a pre-tested questionnaire administered to seventy four consecutive patients admitted at Kenyatta National Hospital after a decision to amputate the lower limb was made. Patients who declined to consent or those previously amputated in other institutions, but required stump revision were excluded. Demographic data included age, gender, education level and employment status of the patients. Clinical data included the indication, type and level of amputation. In majority of the cases, patients could not afford the investigations for determining the level of amputation for those who had peripheral vascular diseases (PVD), so the choice of such level was done on clinical grounds. In situations where conversion to a higher level was required, the amputation level was recorded as the new revised level. The data were grouped and coded then entered into the Statistical Package of Social
Sciences (SPSS) for Windows version 10.5. Results are presented as frequencies and percentages.

\section{RESULTS}

A total of 74 patients underwent 77 lower limb amputations during the study period. The age range was seven months to 96 years (mean $44.8 \pm$ 22.5). Forty six patients $(62.1 \%$ ) were males with a male to female ratio of 1.6:1. Majority of the patients $(89.1 \%)$ had either primary or no formal education. Thirty four patients (45.9\%) were unemployed, and those employed, majority, were self-employed in the informal sector (Table 1).

Peripheral vascular diseases accounted for the majority of LLA (55.3\%), with one third of these patients due to diabetes-related gangrene (Table 2). Tumours accounted for $24.4 \%$ of all amputations with osteogenic sarcoma being the main cause, while road traffic accidents were the main cause of traumarelated amputations. As expected, amputations among teenagers were mainly due to trauma and tumours while peripheral vascular diseases with gangrene were the main cause in elderly patients though notably, there were a significant proportion of young patients with PVD (Figure 1).

Fifteen patients (20\%) had open amputations. Forty two amputations (55\%) were above-the-knee (AKA), three of which were bilateral, 24 were below-

Figure 1

Indications of amputation according to age

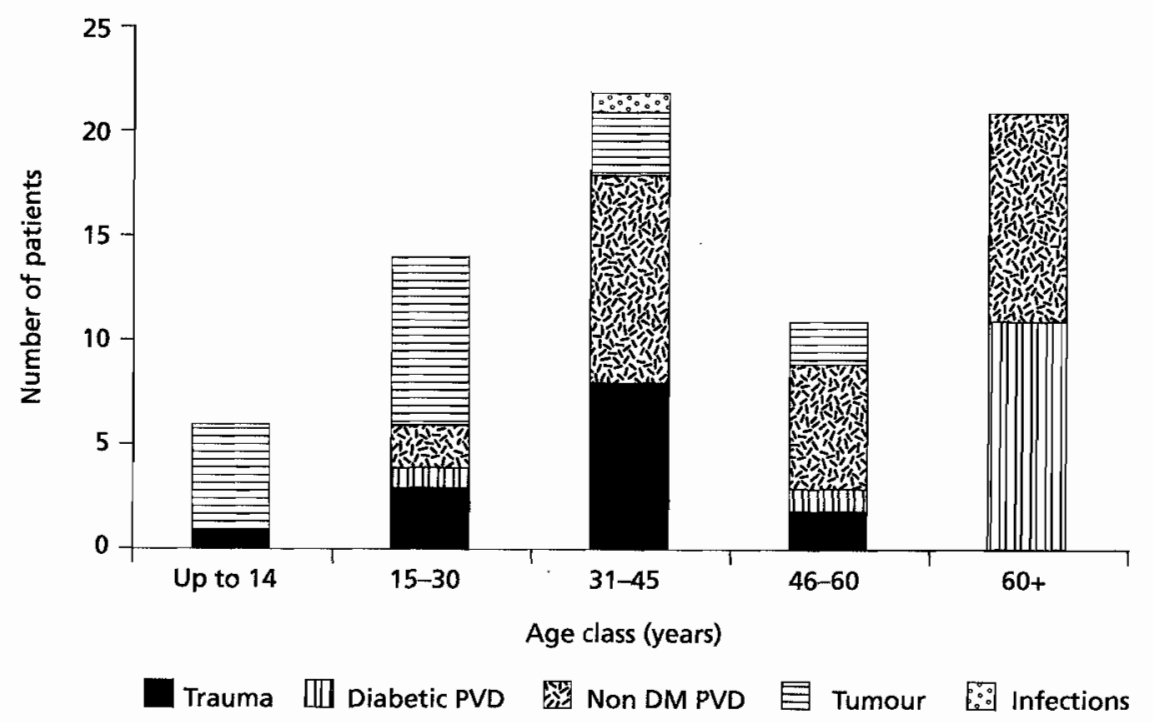

Non $\mathrm{DM}=$ Non diabetic 
the-knee (BKA), four hip disarticulations, three toe, three transmetatarsal and one tarsal amputation.

Five below-knee amputations required conversion to above-knee, while three foot amputations were converted to above-knee. A patient with peripheral vascular disease was likely to undergo below-knee amputation, that with a tumour an above-knee amputation; and a foot amputation if trauma was the cause (Figure 2).

Table 1

Demographic characteristics of the patients

\begin{tabular}{lcccccccc}
\hline $\begin{array}{l}\text { Age class } \\
\text { (Year) }\end{array}$ & \multicolumn{2}{c}{$\begin{array}{c}\text { Gender } \\
\text { Male Female }\end{array}$} & No formal & Primary & Secondary & None & $\begin{array}{c}\text { Employment } \\
\text { Formal }\end{array}$ \\
\hline $0-14$ & 4 & 2 & 0 & 6 & 0 & 0 & 0 & $6^{*}$ \\
(informal)
\end{tabular}

* The employment status of the parents of the minors ( $<18$ years) in these age classes considered instead.

Table 2

Indications for lower limb amputation

\begin{tabular}{llcc}
\hline & Aetiology & No. of patients & $(\%)$ \\
\hline \multirow{2}{*}{ Trauma } & Road traffic accidents & 10 & 13.5 \\
& Burns & 4 & 5.4 \\
\multirow{5}{*}{ Peripheral vascular diseases } & Diabetic-related & 13 & 17.5 \\
& Non diabetic-related & 28 & 37.8 \\
& Osteogenic sarcoma & 12 & 16.2 \\
& Kaposi's sarcoma & 2 & 2.7 \\
& Squamous cell sarcinoma (skin) & 2 & 2.7 \\
& Liposarcoma & 1 & 1.4 \\
& Rhabdomyosarcoma & 1 & 1.4 \\
& Necrotizing fasciitis & 1 & 1.4 \\
\hline
\end{tabular}


Figure 2

Level amputation according to the aetiology

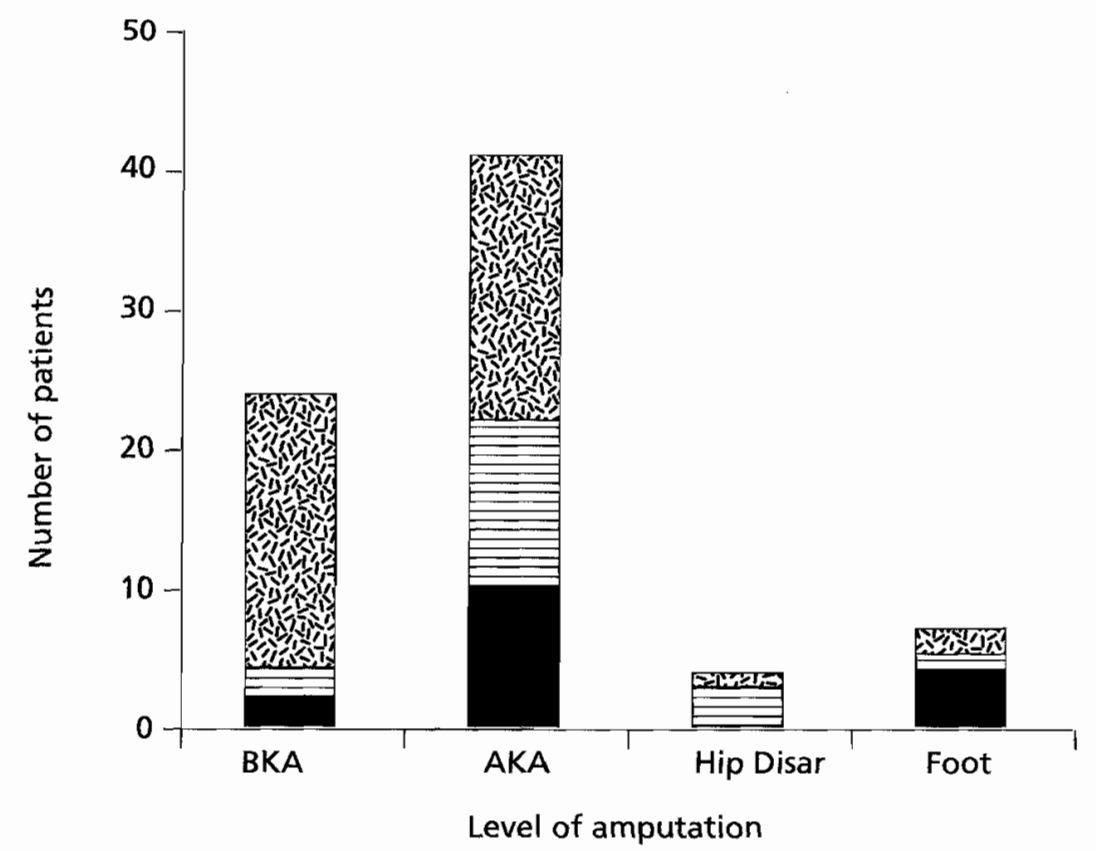

DVD E Tumour 廆 Trauma

\section{DISCUSSION}

Lower limb amputations are performed world wide due to indications that include peripheral vascular diseases, tumours, trauma and infections. However, the contribution of these indications varies depending on several factors such as surgical decision making (2) health delivery systems, regional and ethnic/ racial factors $(10,11)$. Peripheral vascular diseases are the leading cause of lower limb amputations in the western world, due to a largely elderly population (12). Studies done in the African setting however, have found trauma to the extremities and its related complications to be the main indication $(4-7,13)$. The present study found a bimodal pattern in age distribution, with trauma and tumours causing LLA in young patients and PVD in older ones, results similar to those in a previous institutional study (3). Road traffic accidents (RTA) were the leading cause of trauma-related amputations in this study. In $\mathrm{KNH}$, road traffic accidents account for $30 \%$ of trauma admissions and affect mainly young patients with injuries predominantly to the limbs (14). There were no incidents of LLA due to inappropriate splintage of limbs that have otherwise been reported in the literature especially due to traditional bone setters $(6,7,15,16)$. Tumours continue to contribute significantly to LLA in the loco-regional setting $(3,5,13,15,17)$, despite the diminishing role of amputation in the management of limb tumours in the western world (18). In the present study, osteogenic sarcoma was the most common indication of LLA. The high proportion of LLA due to tumours is attributed to late presentation of patients with tumours otherwise amenable to limb saving surgery if managed early $(3,15,17)$. Reasons ranging from poverty to ignorance due to lower level of education as found in this study, account for the late presentation (19). Regional studies have found most of vascular LLAs to be due to diabetic-related complications $(4,7,20,21)$.

In the present study however, majority of the vascular lower limb amputations were not related to diabetes, despite a reported increase in the number of diabetic patients in KNH (9) (Figure 1). Notably, a significant proportion of patients with non-diabetic peripheral vascular disease were less than 46 years of age. None of these patients fulfilled the diagnostic criteria for the so called tropical idiopathic lower limb gangrene (22). None of the patients in this study was investigated for aetiological risks of atherosclerotic peripheral vascular disease or 
was screened for antibodies against the Human immunodeficiency virus (HIV) or was on antiretroviral therapy. Conditions such as dyslipidaemia, homocysteinaemia and hypercoagulable states are independent risk factors for premature peripheral atherosclerosis (23). Individuals with premature peripheral atherosclerosis develop symptoms of PVD before the age of 50 years, and the prognosis for the majority of them is poor with a significant proportion eventually requiring major limb amputations $(24,25)$. Peripheral arterio-occlusive diseases causing limb ischaemia in young patients have also been described in Human immunodeficiency virus (HIV) positive patients $(26,27)$. These are related to factors such as hypercoagulable states (28) use of antiretroviral drugs (29) and also an arteritis distinct from atherosclerosis causing large-vessel occlusive disease (30).

Above-knee was the most frequent level of amputation. This is mainly due to the fact that osteogenic sarcoma, which was the most common tumour, affects in most cases, the distal femur and proximal tibia. Despite that in most of the vascular amputations the level had to be determined clinically, both above-knee and below-knee amputations were performed in equal proportions for patients with PVD, giving a BKA:AKA ratio of 1:1 as reported in other literature (31-33). An above knee amputee spends more energy to ambulate (34). Efforts at preserving the knee would afford greater mobility after rehabilitation, since majority of the amputees are young and in the economically active age.

In conclusion, this study found peripheral vascular diseases to be the main indication for lower limb amputations at Kenyatta National Hospital contrary to previous institutional and locoregional studies which report trauma as the leading cause. Further investigation into vascular causes is therefore recommended.

\section{ACKNOWLEDGEMENTS}

To Kenyatta National Hospital management for allowing us to conduct the study in the hospital, and Dr. H.S. Saidi for accepting to read the manuscript.

\section{REFERENCES}

1. The Global Lower Extremity Amputation Study Group. Epidemiology of lower extremity amputation in centres in Europe, North America and East Asia. Brit. J. Surg. 2000; 87: 328-337.

2. Cornelly J., Airey M. and Chell S. Variation in clinical decision is a partial explanation for geographical variation in lower extremity amputation rates. Brit.J. Surg. 2001; 88: 529-535.

3. Mbindyo B.S. Lower limb amputations in Kenyatta National Hospital. East Afr. Med. J. 1978; 55: 458-461.

4. Muyembe V.M. and Muhinga M.N. Major limb amputations in a Provincial General Hospital in Kenya. East Afr. Med. J. 1999; 76: 163-166.

5. Kidmas A.T., Nwadiaro C.H. and Igun G.O. Lower limb amputation in Jos, Nigeria. East Afr. Med. J. 2004; 81: $427-429$.

6. Umaru R.H., Gali B.M. and Ali N. Role of inappropriate traditional splintage in limb amputation in Maiduguri, Nigeria. Ann. Afr. Med. 2004; 3: 138-140.

7. Onuminya J.E., Obekpa P.O., Ihezue H.C., et al. Major amputations in Nigeria: A plea to traditional bone setters. Trop. Doct. 2000; 30: 133-135.

8. Amos A.F., McCarty D.J. and Zimmet P. The rising global burden of diabetes and its complications: estimates and projections to the year 2010. Diabet. Med. 1997; 14 (Suppl 5): S1-85.

9. Maganga H.M. Lower extremity amputations in diabetic patients as seen in Kenyatta National Hospital. University of Nairobi; Master of Medicine (Surgery), Dissertation. 2001.

10. Wennberg J.E. Understanding geographic variation in health care delivery. N. Engl. J. Med. 1999; 340: 52-53.

11. Wrobel JS., Mayfield J.A. and Reiber G.E. Geographic variation of lower extremity major amputation in individuals with and without diabetes in the Medicare population. Diabetes Care. 2001; 24: 860-864.

12. Gregory-Dean A. Amputations: Statistics and Trends. Ann. Roy Coll. Surg. Engl. 1991; 73: 137-142.

13. Solagberu B.A. The scope of amputations in a Nigerian teaching hospital. Afr. J. Med. Sci. 2001; 30: 225-227.

14. Saidi H.S., Macharia W.M. and Ating'a J.E.O. Outcome for hospitalised road trauma patients at a tertiary hospital in Kenya. Eur. J. Trauma. 2005; 31: 401-406.

15. Yakubu A., Muhammad I. and Mabogunje O.A. Major limb amputation in adults, Zaria, Nigeria. J.R. Coll. Surg. Edinburgh. 1996; 41: 102-104. 
16. Eshete $M$. The prevention of traditional bone-setter's gangrene J. Bone Joint Surg. Brit. 2005; 87: 102-103.

17. Hassan A.W. Major limb amputations at Maiduguri Teaching Hospital. Medicare. 1992; 5: 13-15.

18. Rodney $S$. The diminishing role of amputation in the management of malignant tumours of bone. Ann. Roy Coll. Surg. Engl. 1991; 73: 165-169.

19. Ndegwa L.K., Karimurio J., Okello R.O. and Adala H.S. Barriers to utilisation of eye services in Kibera slums of Nairobi. East Afr. Med. J. 2005; 82: 507-509.

20. Akiode O., Olusola Shonubi A.M., Adewale M. and Sule G. Major limb amputations: An audit of indications in a suburban surgical practice. J. Natl. Med. Assoc. 2005; 97: 74-78.

21. Mohammed I.A., Ahmed A.R. and Ahmed M.E. Amputations and prostheses in Khartoum. J. Roy Coll. Surg. Edinb. 1997; 42: 248-251.

22. Musa A.A. A review of diagnosis and modes of presentation of tropical idiopathic lower limb gangrene. Afr. Hlth. Sci. 2006; 6: 49-50.

23. Valentine R.J. Premature peripheral atherosclerosis. Cardiovasc. Surg. 1993; 1: 473-380.

24. Levy P.J., Hornung C.A., Haynes J.L. and Rush D.S. Lower extremity ischemia in young adults younger than 40 years of age: A community-wide survey of premature atherosclerotic arterial disease. J. Vasc. Surg. 1994; 19: 873-881.

25. McReady R.A., Vincent A.E., Schwartz R.W., et al. Atherosclerosis in the young: A virulent disease. Surg. 1984; 96: 863-868.
26. Mulaudzi T.V., Robbs W., Pillay B., et al. Thrombectomy in HIV related peripheral arterial thrombosis: A preliminary report. Eur. J. Endovasc. Surg. 2005; 30: 102-106.

27. Nair R., Robbs J.V., Chetty R., et al. Occlusive arterial disease in HIV-infected patients: A preliminary report. Eur. J. Endovasc. Surg. 2000; 20: 353-357.

28. Feffer S.E., Fox R.L., Orsen M.M., et al. Thrombotic tendencies and correlation with clinical status in patients infected with HIV. South Med. J. 1995; 88: 1126-1130.

29. GeorgeS.L., Swendells S., Knudson R., et al. Unexplained thrombosis in HIV-infected patients receiving protease inhibitors: report of seven cases Amer. J. Med. 1999; 107: 624-630.

30. Chetty R., Batitang S. and Nair R. Large artery vasculopathy in HIV-positive patients: Another vasculitic enigma. Hum. Pathol. 2000; 31: 374-379.

31. Olasinde A.A., Oginni L.M., Bankole J.O., et al. Indications for amputation in Ile-Ife, Nigeria. Niger. J. Med. 2002; 11: 118-121.

32. Nehler M.R., CoIl J.R., Hiatt W.R., et al. Functional outcome in a contemporary series of major lower extremity amputations. J. Vasc. Surg. 2003; 38: 7-14.

33. Kazmers A., M.S.P.H., Perkins J.A., et al. Major lower extremity amputations in Veterans Affairs Medical Centers. Ann. Vasc. Surg. 2000; 14: 216-222.

34. Waters R.L. Energy costs of walking amputees' influence of amputation. J. Bone Joint Surg. Amer. 1976; 58: $42-47$. 